\title{
Operating Reserves in ReEDS
}

Brian Sergi and Wesley Cole

December 2021 


\section{Operating reserves overview}

Operating reserve product types:

- Frequency Responsive Reserves: the ability to resist or respond to changes in frequency

- Regulation Reserve (reg): the ability to respond to regular small fluctuations in loadsupply imbalances

- Contingency (spinning) Reserve (spin): the ability to respond to a major unit or transmission outage

- Flexibility Reserves (flex): the ability to provide following and ramping needs (also known as "ramping reserves")

Reserves are designed to maintain reliability despite inherent variability and uncertainty in demand and supply, including variable renewable energy (VRE)

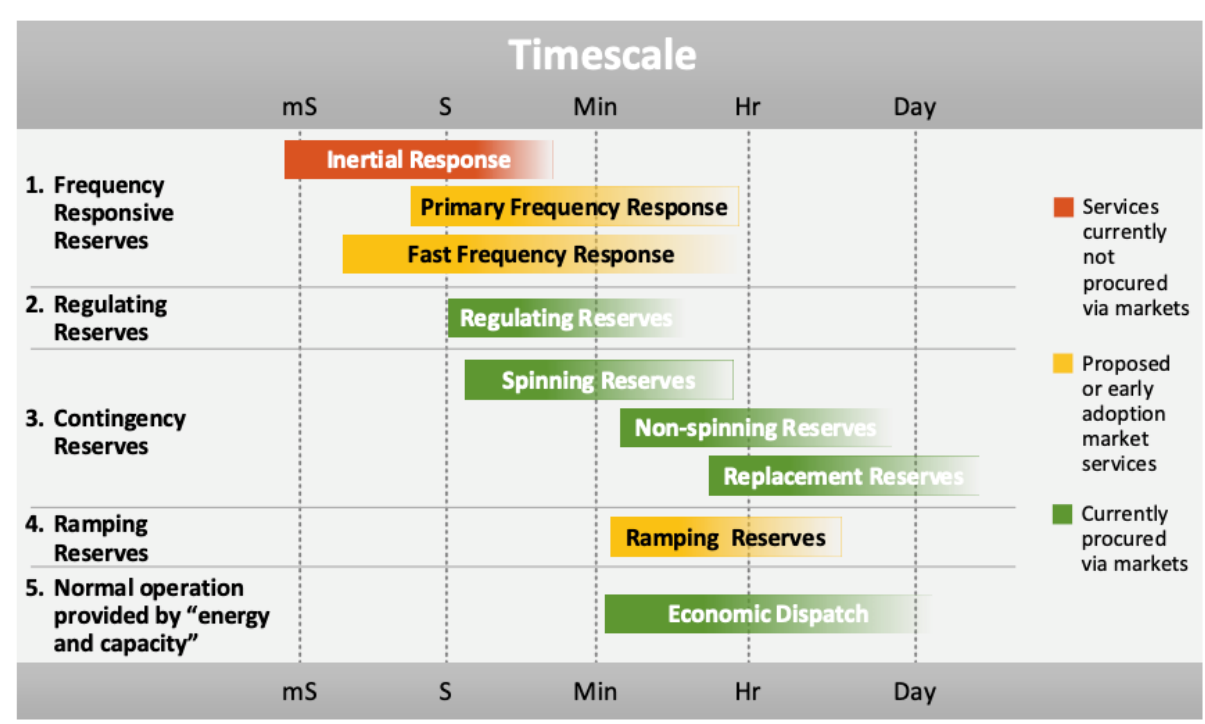

Source: Denholm, Paul L., et al. An Introduction to Grid Services: Concepts, Technical Requirements, and Provision from Wind. National Renewable Energy Laboratory, Golden, CO, 2019, https://www.osti.gov/biblio/1493402. 


\section{Operating reserves in ReEDS}

ReEDS models three categories of reserves (reg, spin, and flex)

- Reserve requirements quantities are functions of load and VRE share and vary by product.

- Requirement levels are calculated based on methods from the WECC TEPPC*, outlined in Lew et al. (2013) and reproduced in the table below.

- Reserves effectively modeled as "up" reserves.

Operating reserve requirements as a function of load or VRE generation/capacity

\begin{tabular}{|c|c|c|c|}
\hline & $\begin{array}{c}\text { Load } \\
\text { (\% of load) }\end{array}$ & $\begin{array}{c}\text { Wind } \\
\text { (\% of generation) }\end{array}$ & $\begin{array}{c}\text { PV } \\
\text { (\% of capacity) }\end{array}$ \\
\hline reg & $1 \%$ & $0.5 \%$ & $0.3 \%$ \\
\hline spin & $3 \%$ & -- & -- \\
\hline flex & -- & $10 \%$ & $4 \%$ \\
\hline
\end{tabular}

*Western Electricity Coordinating

Council Transmission Expansion

Planning Policy Committee 


\section{Operating reserves in ReEDS}

Ability of generation technology to supply reserves is dependent on their ability to ramp

- Response time requirements by reserve type:

\begin{tabular}{|l|c|c|c|}
\hline & reg & spin & flex \\
\hline Response time (minutes) & 5 & 10 & 60 \\
\hline
\end{tabular}

- $\quad$ Ramp rate] $\times$ [Response time $]=$ fraction of resource than can provide reserve (reserve_frac)

- By default, ReEDS modeling does not allow pre-curtailment of VRE resources (wind/solar) to provide operating reserves 


\section{Availability of technologies to provide operating reserves}

\begin{tabular}{|c|c|c|c|c|}
\hline & \multirow{2}{*}{$\begin{array}{l}\text { Assumed Ramp } \\
\text { Rate }(\% / \mathrm{min})\end{array}$} & \multicolumn{3}{|c|}{ Ramp Rate * Ramp Time = Upper Bound (\% of online capacity) } \\
\hline & & Spinning & Regulation & Flexibility \\
\hline Gas-CT & 8 & $8 * 10=80$ & $8 * 5=40$ & $8 * 60=480$, so 100 \\
\hline Gas-CC & 5 & $5 * 10=50$ & $5 * 5=25$ & $5 * 60=300$, so 100 \\
\hline Coal & 2 & $2 * 10=20$ & $2 * 5=10$ & $2 * 60=120$, so 100 \\
\hline *Nuclear & 2 & $2 * 10=20$ & $2 * 5=10$ & $2 * 60=120$, so 100 \\
\hline **Geothermal & 4 & $4 * 10=40$ & $4 * 5=20$ & $4 * 60=240$, so 100 \\
\hline CSP w/ Storage & 10 & $10 * 10=100$ & $10 * 5=50$ & $10 * 60=600$, so 100 \\
\hline **Biopower & 4 & $4 * 10=40$ & $4 * 5=20$ & $4 * 60=240$, so 100 \\
\hline Oil/Gas Steam & 4 & $4 * 10=40$ & $4 * 5=20$ & $4 * 60=240$, so 100 \\
\hline Hydro (dispatchable) & 100 & \multirow{2}{*}{\multicolumn{3}{|c|}{ No Upper Bound }} \\
\hline$* * *$ Storage & 100 & & & \\
\hline
\end{tabular}

Sources:

Bloom, Aaron, et al. Eastern Renewable Generation Integration Study. National Renewable Energy Laboratory, Golden, CO, 2016, https://www.osti.gov/biblio/1318192. See Table 6 for NG-CT, NG-CC, Coal, Oil/Gas Steam

Jorgenson, Jennie, et al. Estimating the Performance and Economic Value of Multiple Concentrating Solar Power Technologies in a Production Cost Model. National Renewable Energy Laboratory, Golden, CO, 2013, https://www.osti.gov/biblio/1260920. See Table 3 for CSP.

\section{Upper bound determines}

maximum fraction of online capacity that generators could provide as reserves (reserve_frac)

* By default nuclear is precluded from providing operating reserves in ReEDS, but this can be enabled using the GSw_NukeFlex switch

**Geothermal and biopower values are assumed to be the same as oil/gas steam units. In practice, geothermal plants typically do not ramp given their zero or near-zero variable costs, and therefore only provide energy and not operating reserves.

***Storage includes batteries, pumped storage hydropower (PSH), and compressed air energy storage (CAES). 


\section{Regional considerations}

All operating reserves must be supplied within one of 18 modeldefined Regional Transmission Organization (RTO) regions.

Reserves cannot be traded between RTO regions (e.g., prohibits New York hydro from meeting regulation reserve requirement in Florida)

By default, reserves can be traded between balancing areas (BAs) within an RTO

- Model switches allow for testing sensitivities that preclude or penalize inter-BA reserve trading

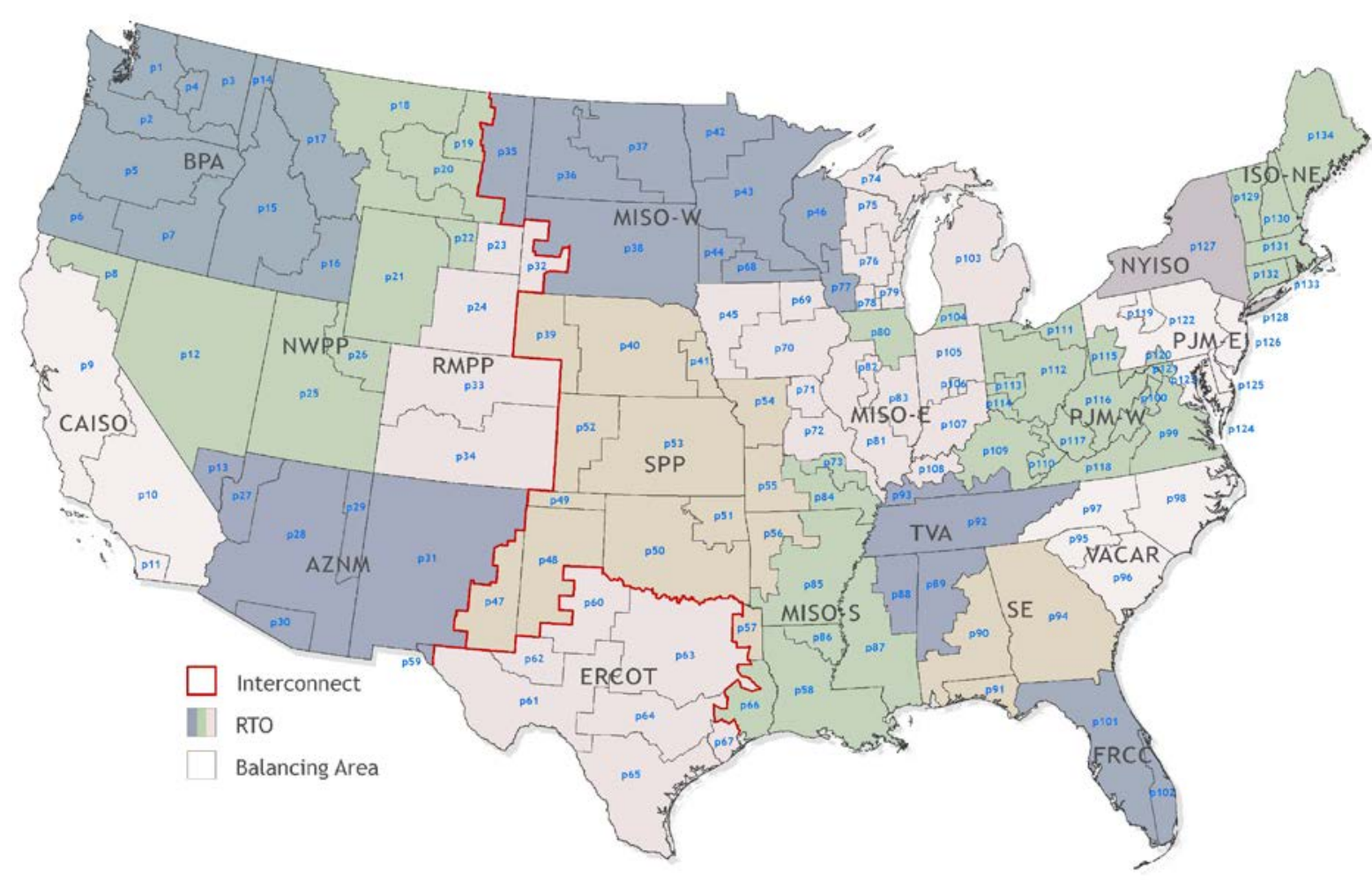

Source: Ho, Jonathan, et al. Regional Energy Deployment System (ReEDS) Model Documentation: Version 2020. 


\section{Cost for providing regulation reserves}

Opportunity costs are captured in the ReEDS formulation for all reserve products. However, additional costs are included for regulation reserves to account for the cost of following a rapidly changing signal.

Generator costs are taken from Table 3 in Hummon et al. (2013) (reproduced here).

- These costs are in 2013\$.

- Because ReEDS does not clearly distinguish between coal type, we use $\$ 12.5 / \mathrm{MW}-\mathrm{h}$ for all coal technologies.

- Gas-CT, geothermal, biopower, land-fill gas, and CAES are all assumed to provide

\begin{tabular}{|c|c|}
\hline Generator Type & Cost (\$/MW-h) \\
\hline Supercritical Coal & 15 \\
\hline Subcritical Coal & 10 \\
\hline Combined Cycle & 6 \\
\hline Gas/Oil Steam & 4 \\
\hline Hydro & 2 \\
\hline Pumped Storage Hydropower & 2 \\
\hline
\end{tabular}

Source: Hummon, Marissa, et al. Fundamental Drivers of the Cost and Price of Operating Reserves. National Renewable Energy Laboratory, Golden, CO, 2013, https://www.osti.gov/biblio/1220216. regulation reserves at the same cost as gas/oil steam. 
Recent modeling changes related to operating reserves

1. Accounted for efficiency losses for any storage technology that provides regulation reserves.

2. Included a requirement that storage have sufficient energy to cover reserves + generation in a timeslice.

3. Refined constraints governing whether generators must be on to provide reserves.

4. Added a cost to provide spinning reserves for generators that have heat rates. 


\section{Storage efficiency losses}

Motivation: ReEDS accounts for storage losses when charging to provide energy, and therefore should also consider losses for any charging associated with providing regulation reserves.

Storage losses from provided regulation reserves calculated as:

reg_provided / $2 *(1$ - storage_eff $(i, t)) *$ reg_energy_frac

- $\quad$ Assuming an energy neutral signal (i.e., the storage will return to its state of charge at the end of the time period), storage is only expected to be charging half the time when providing regulation reserve. Accordingly, we calculate efficiency losses for half of the regulation reserve provided (reg_provided).

- $\quad$ storage_eff $(i, t)$ is the round-trip efficiency for storage of technology $i$ in year $t$

- reg_energy_frac is the fraction of regulation reserves that will result in generation, also known as the dispatch to contract ratio (assumed to be $15 \%$ based on Ferreira et al., 2013)

Example: A battery with $85 \%$ roundtrip efficiency provides $10 \mathrm{MW}$ of regulation reserves for 1 hour. The losses from providing these reserves are $10 / 2 *(1-0.85) * 0.15=0.1125 \mathrm{MW}-\mathrm{h}$ 


\section{Storage state of charge}

Motivation: Previously, the model would allow for storage to provide operating reserves even if it had no available state-of-charge. This might overstate storage's ability to provide reserves.

A new constraint was added to ensure that storage has sufficient state of charge to provide operating reserves (eq_storage_opres)

- Formulation included in appendix to this presentation (slide 31)

If storage is also discharging, it can only provide operating reserves using the remaining energy

- E.g., if the starting state of charge of a battery is $100 \mathrm{MWh}$, and it discharges $60 \mathrm{MWh}$, then it can use the remaining $40 \mathrm{MWh}$ for operating reserves in the same timeslice. 


\section{Generator dispatch and reserves}

Motivation: Generators with minimum generation levels may not be able to provide reserves without being committed.

ReEDS' representation of "unit commitment" was expanded to two constraints to better control the online status of generators when providing operating reserves:

- Based on generators ability to respond (reserve_frac; see table on slide 5).

- Generators with reserve_frac <= 0.5 must generate during the same timeslice (these are the less-flexible generators).

- Generators with reserve_frac >0.5 must generate sometime during the same day (these are the more flexible generators).

Prior to this change, all generators were treated using the more flexible generation option, which may have overstated the ability of inflexible generators to provide reserves. 


\section{Heat rate penalty}

Motivation: Generators that have heat rates may be less efficient if they reduce their set points to ensure headroom for reserves. Capturing this dynamic better captures the cost of providing operating reserves.

Fossil generators are given an additional penalty on cost to provide spinning reserves

- Intended to represent costs of operating at lower efficiencies (i.e., less efficient point on heat rate curve)

Penalty factor is derived from the increase in heat rate at $50 \%$ load relative to $100 \%$ load

- Based on heat rate curves in the PLEXOS database used for the North American Renewable Integration study (NARIS, 2021), depicted in the chart to the right

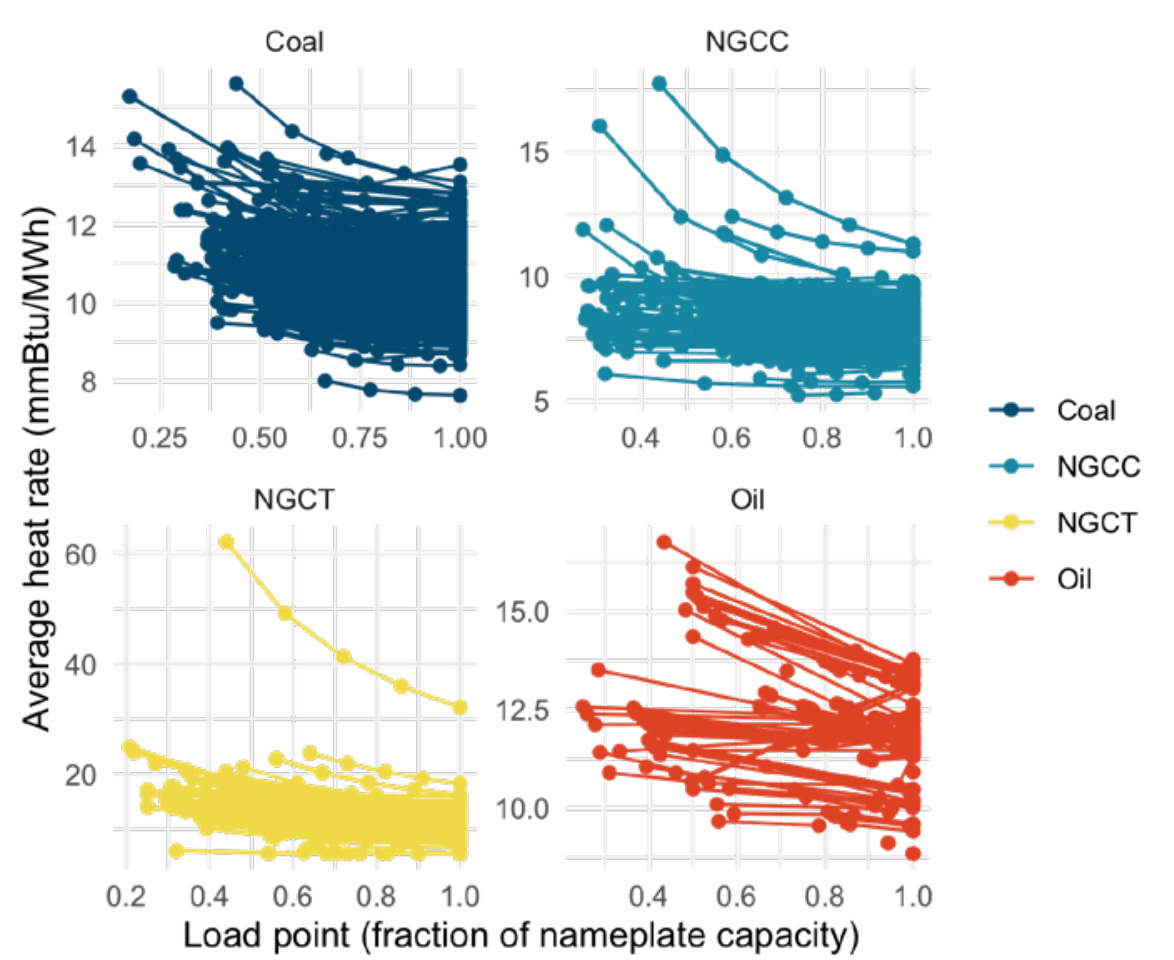




\section{Release of model with updated reserve formulations}

All model changes described above have been included in the 2021 version of the ReEDS model.

This model version was made publicly available in November with the release of the 2021 Standard Scenarios.

- Available at https://www.nrel.gov/analysis/reeds/. 


\section{Operating reserve switches in ReEDS}

\section{To facilitate operating reserve analysis, these switches were added to the model:}

\begin{tabular}{|l|l|l|} 
Switch name & Turn on/off operating reserve constraints & $\mathbf{0}=$ off, 1 = on (default) \\
\hline GSW_OpRes & $\begin{array}{l}\text { Suffix for filename of inputs for operating reserve costs; users } \\
\text { can use one of two included files or create their own cost } \\
\text { input file }\end{array}$ & $\begin{array}{l}\text { default = costs only included for regulation reserves (default) } \\
\text { market = cost of providing spinning, regulation, and flexibility } \\
\text { for all generators given value of clearing prices in 2017* }\end{array}$ \\
\hline GSw_OpResReqMult & Multiplier for total requirement of operating reserves & Any positive number (default is 1) \\
\hline GSW_OpResTrade & $\begin{array}{l}\text { Turn on/off the ability to trade operating reserves across } \\
\text { balancing areas }\end{array}$ & $\mathbf{0}=$ off, 1 = on (default) \\
\hline GSw_OpResTradeMult & $\begin{array}{l}\text { Multiplier on how much transmission capacity is required for } \\
\text { each unit of operating reserves traded between balancing } \\
\text { areas }\end{array}$ & Any positive number (default is 1) \\
\hline GSW_OpresFromVRE** & $\begin{array}{l}\text { Turn on/off the ability of VRE resources to provide operating } \\
\text { reserves }\end{array}$ & $\mathbf{0}=$ off (default), 1 = on \\
\hline GSW_OpresFromStorage** & $\begin{array}{l}\text { Turn on/off the ability of storage to provide operating } \\
\text { reserves (includes batteries, pumped storage hydro, and } \\
\text { CAES) }\end{array}$ & $\mathbf{0}=$ off, $\mathbf{1}=$ on (default) \\
\hline
\end{tabular}

*Based on findings in Denholm et al., An Introduction to Grid Services: Concepts, Technical Requirements, and Provision from Wind. National Renewable Energy Laboratory, Golden, CO, 2019, https://www.osti.gov/biblio/1493402.

** These switches are not included in the 2021 open access version of ReEDS but will be available in the next release. When turned on, it is assumed that VRE can ramp $100 \%$ of its capacity and thus has a reserve_frac $=1$. 


\section{Testing Performed}

We compared operating reserve outcomes in ReEDS with hourly dispatch from PLEXOS, a production cost modeling tool (PCM).

- Finer temporal resolution (hourly), with chronological modeling of storage state-of-charge.

- Better representation of fossil generator constraints (e.g., min stable levels, ramping).

PLEXOS model developed using the ReEDS-to-PLEXOS translation tool

- Based on reference case ReEDS scenario for the continental U.S., run biennially through 2050.

- PLEXOS model run zonally, with spatial resolution matching ReEDS BAs.

Despite some of the enhanced resolution and detail, PLEXOS doesn't necessarily represent the "ground truth" for these models. However, it is a helpful source of comparison. 


\section{Comparison with PLEXOS}

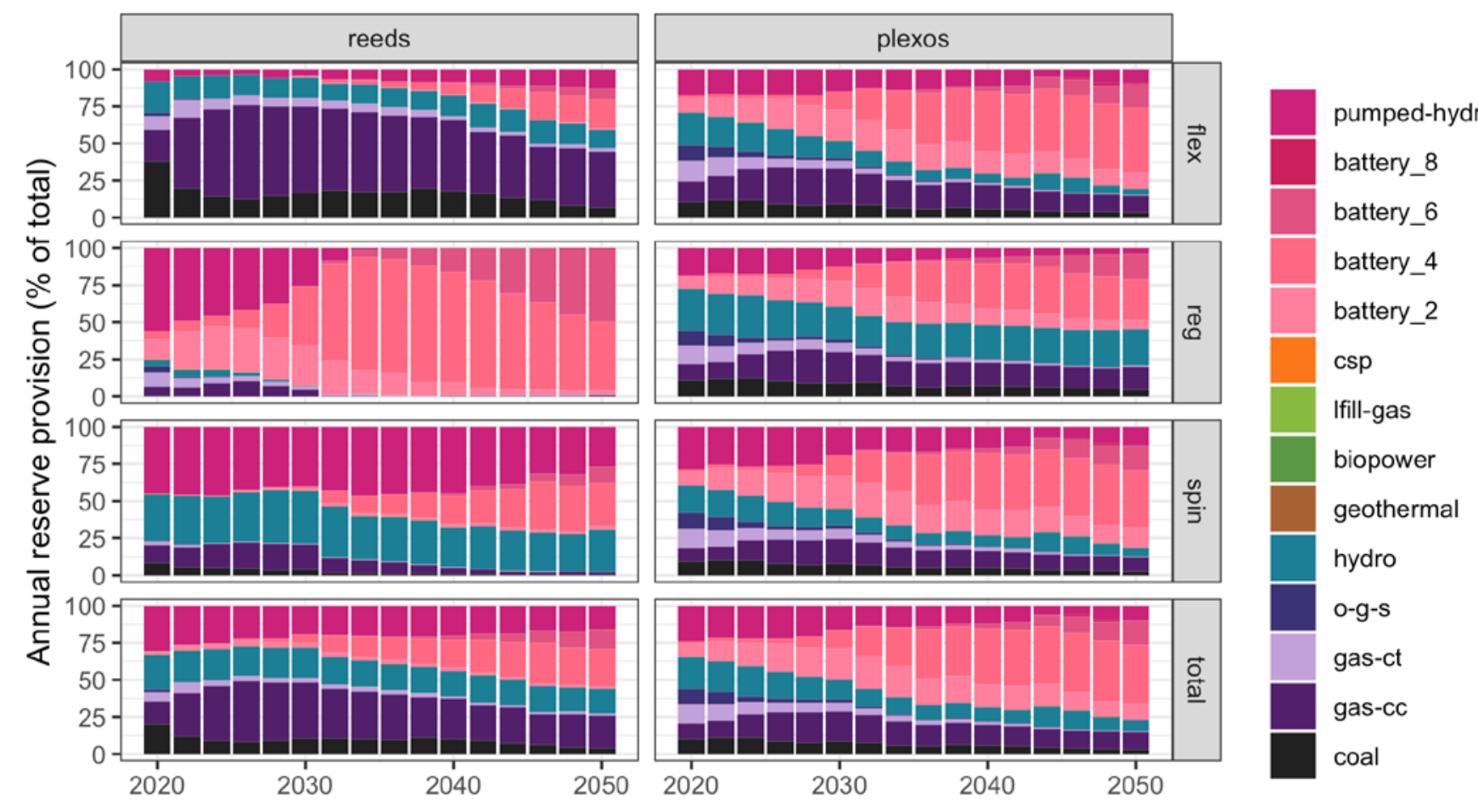

ReEDS and PLEXOS show some differences in which technologies are dispatched for specific reserve products.

- ReEDS overestimates hydro provision of spinning reserve and underestimates regulation.

- $\quad$ ReEDS utilizes more gas generation for flex reserves than PLEXOS.

Despite differences by product, the total share of reserve provision by technology across is comparable.

- $\quad$ More gas used for reserves in ReEDS than in PLEXOS; may reflect impact of additional generator constraints.

- $\quad$ Storage is the largest provider of reserves across both modeling approaches, particularly for future scenarios.

Some differences expected given the difference in temporal resolution and generation characteristics between capacity expansion (ReEDS) and production cost (PLEXOS) models 


\section{Testing Performed}

We also performed sensitivities on some of the new operating reserve switches to understand how they affect capacity buildouts and costs in ReEDS. These sensitivities included:

1. Penalties on trading operating reserves across regions (GSw_OpResTradeMult)

2. Allow/disallow VRE to provide reserves (GSW_OpresFromVRE)

3. Allow/disallow storage to provide reserves (GSW_OpresFromStorage)

4. Allow ReEDS to endogenously determine reserve prices / pay for operating reserves at the 2017 market clearing prices (GSw_OpResCost)

We test different combinations of sensitivities 2-4 for both a reference case and a case with a $100 \%$ clean energy requirement by $2050 *$.

\section{VRE buildout

Reference

High VRE

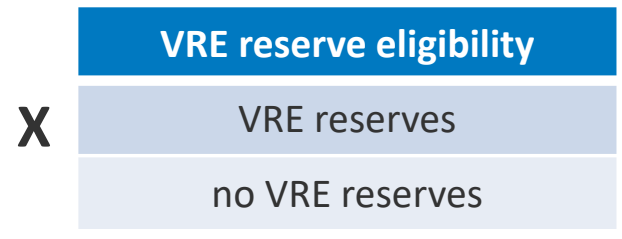

Storage reserve eligibility storage reserves

no storage reserves
Reserve cost method

Endogenous

Based on 2017 market prices 


\section{ReEDS sensitivity testing: Penalty on trading reserves}

National average reserve prices by product ( $\$ / M W-h)$
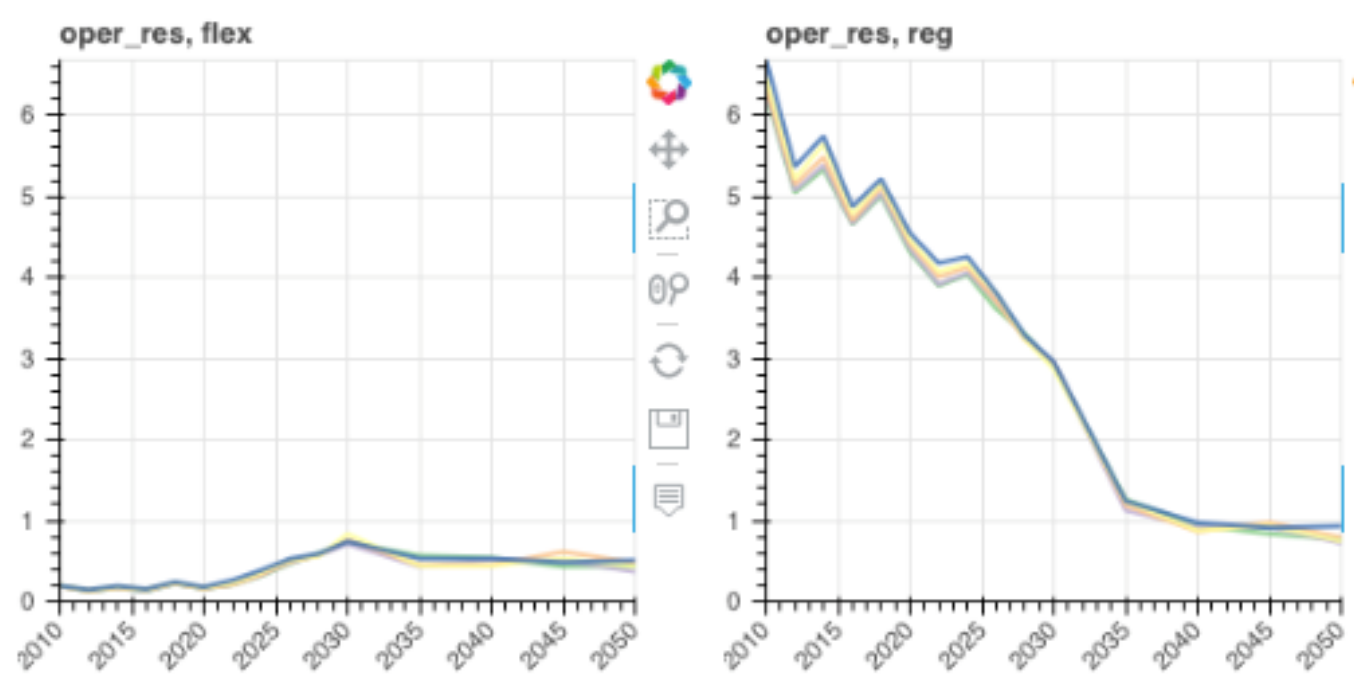

Multipliers for trading operating reserves have little impact on reserve prices or installed capacity 


\section{ReEDS sensitivity testing: Penalty on trading reserves}

Multipliers for how much transmission must be allocated to for reserves to be traded between BAs (ref: 1 means trading $1 \mathrm{MW}$ required $1 \mathrm{MW}$ of transmission)

U.S. installed capacity (GW, difference from reference)
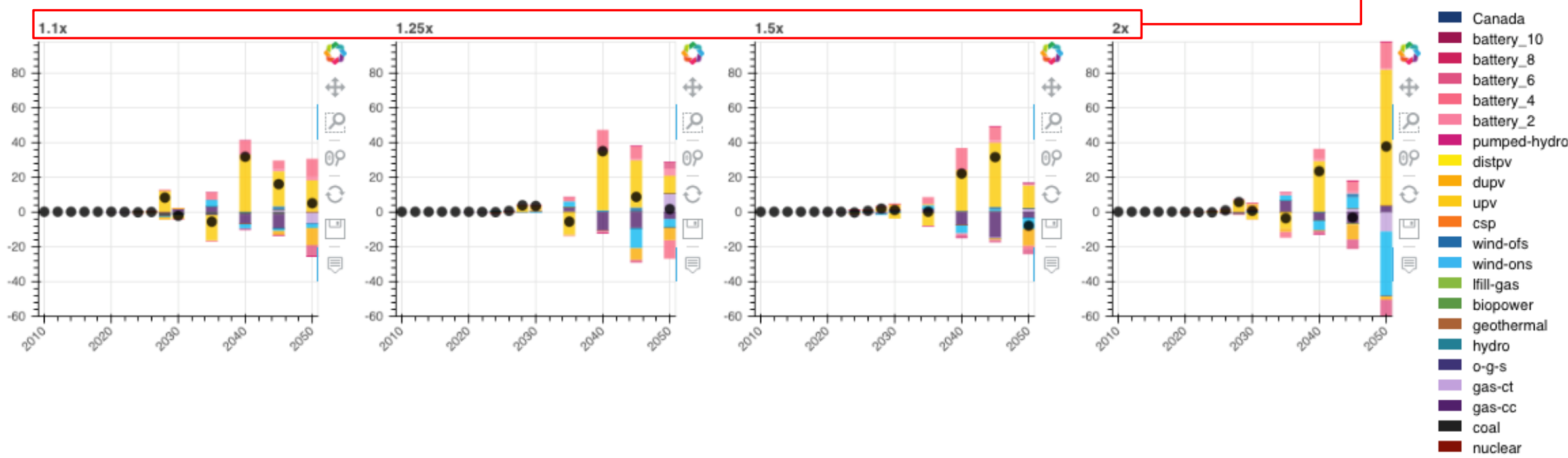

Multipliers for trading operating reserves have little impact on reserve prices or installed capacity 


\section{ReEDS sensitivity testing: Installed capacity}

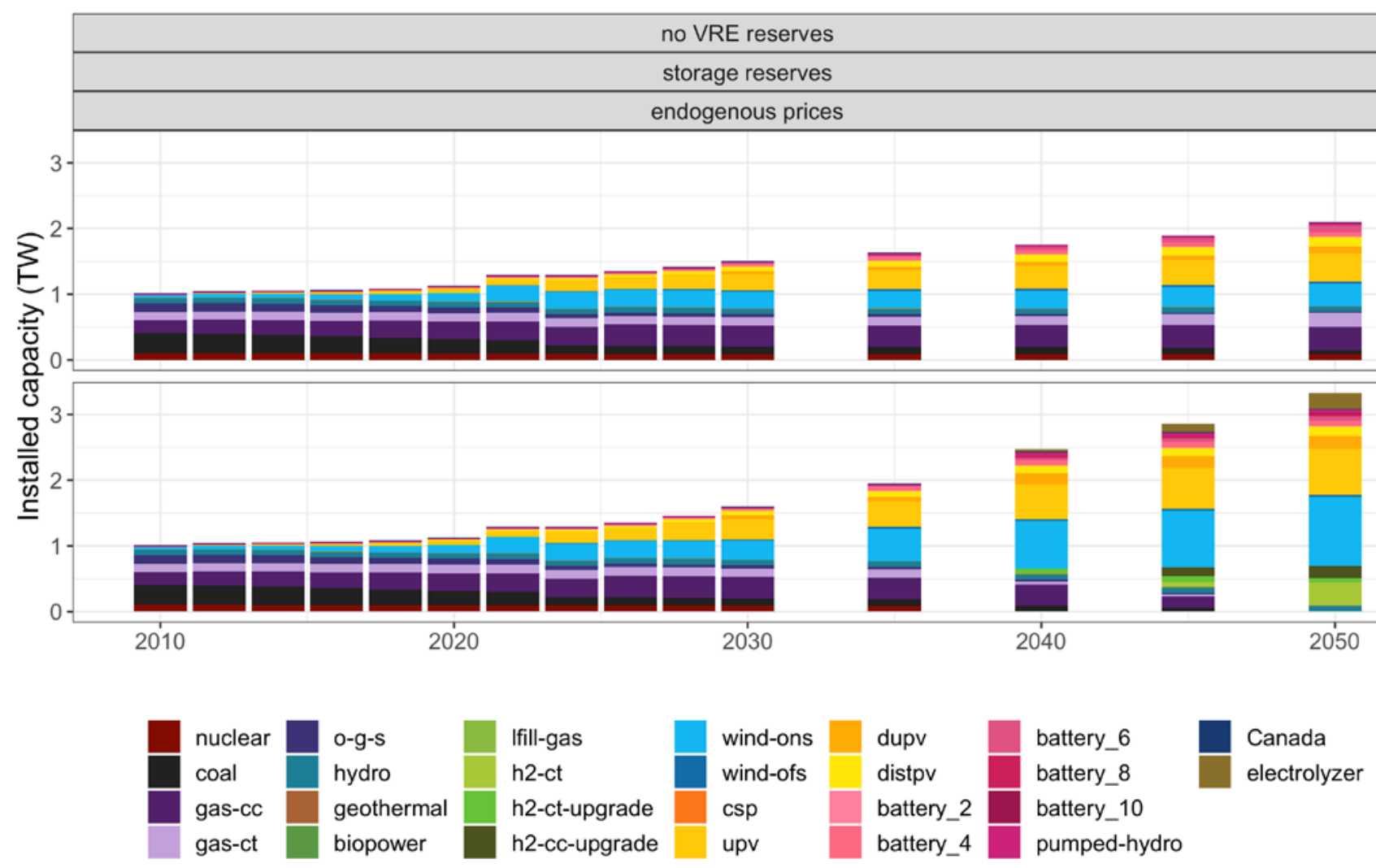

Default settings

in ReEDS for

operating reserves switches 


\section{ReEDS sensitivity testing: Installed capacity}

Difference in capacity from default settings

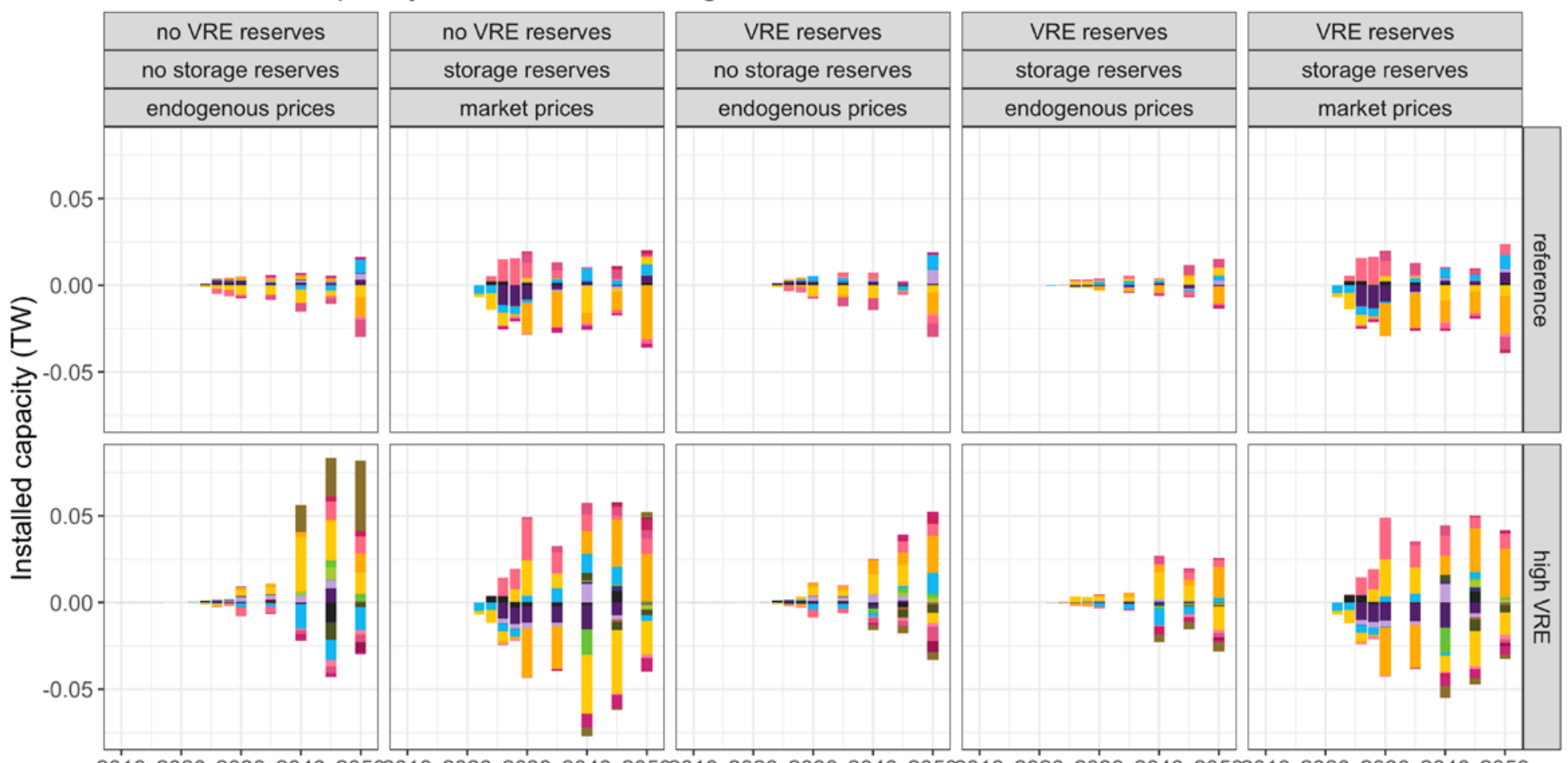

$20102020203020402050201020^{\prime} 2020302040205020^{\prime} 1020202030204020502010202020302040205020102020203020402050$
Capacity differences are small relative to system size

( $<3 \%$ of total) electrolyzer smr-ccs

Canada

pumped-hydro battery 10

battery_8

battery_6

battery 4

battery_2

distpv

dupv

upv

csp

wind-ofs

wind-ons h2-cc-upgrade h2-ct-upgrade h2-cc h2-ct Ifill-gas biopower geothermal hydro

o-g-s

gas-ct gas-cc cofire coal nuclear 


\section{ReEDS sensitivity testing: System Costs}

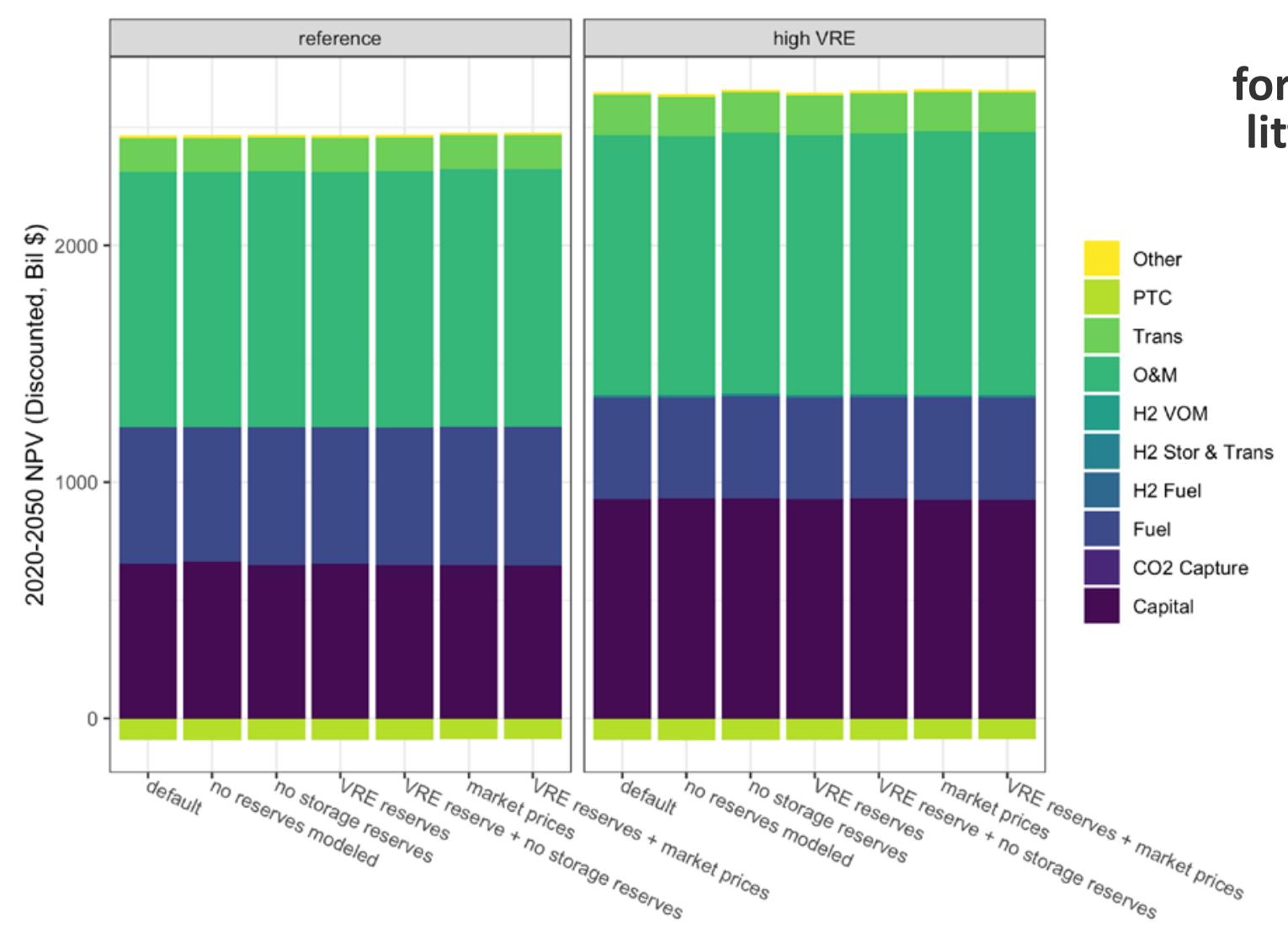

Reserve eligibility/pricing formulations tested have relatively little impact on total system costs 


\section{ReEDS sensitivity testing: Annual generation}

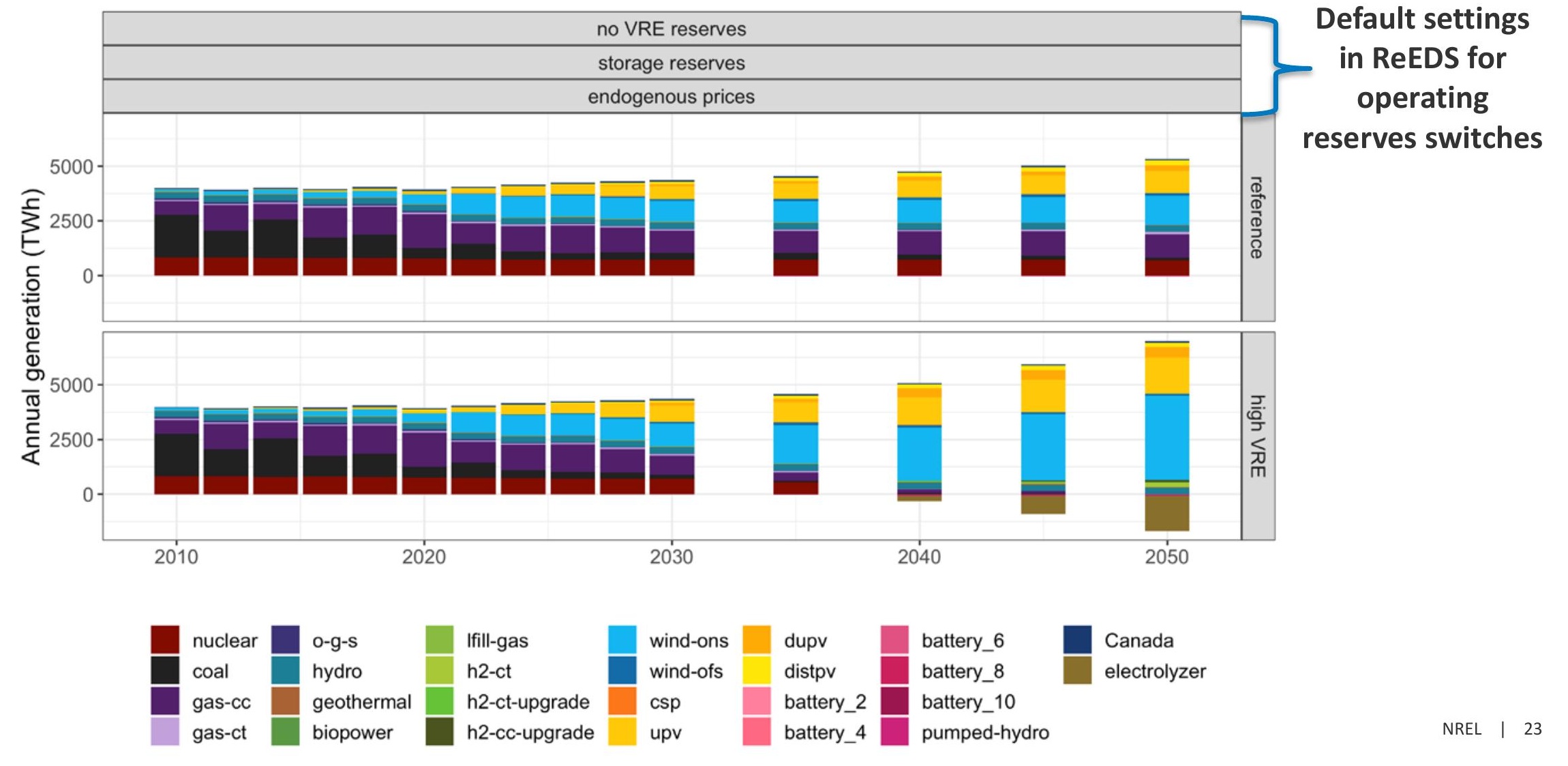

Default settings in ReEDS for operating reserves switches 


\section{ReEDS sensitivity testing: Reserve provision}

\section{Default settings}

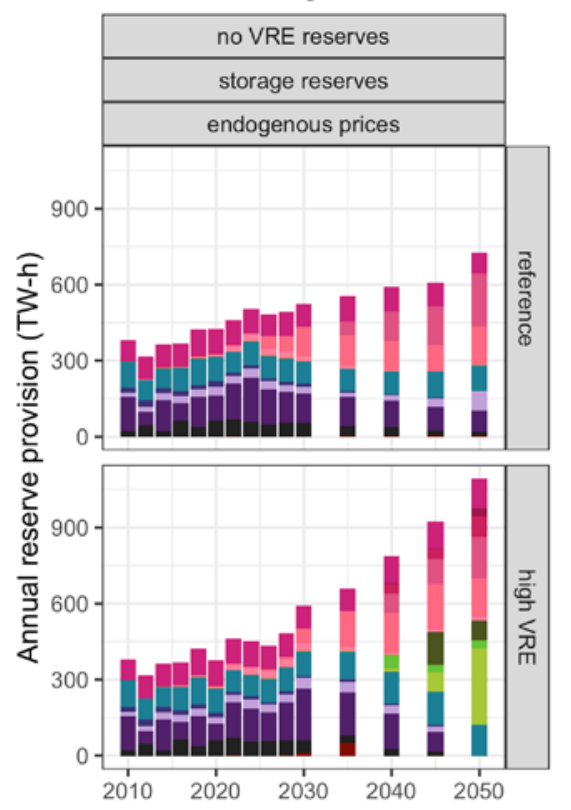

Difference from default

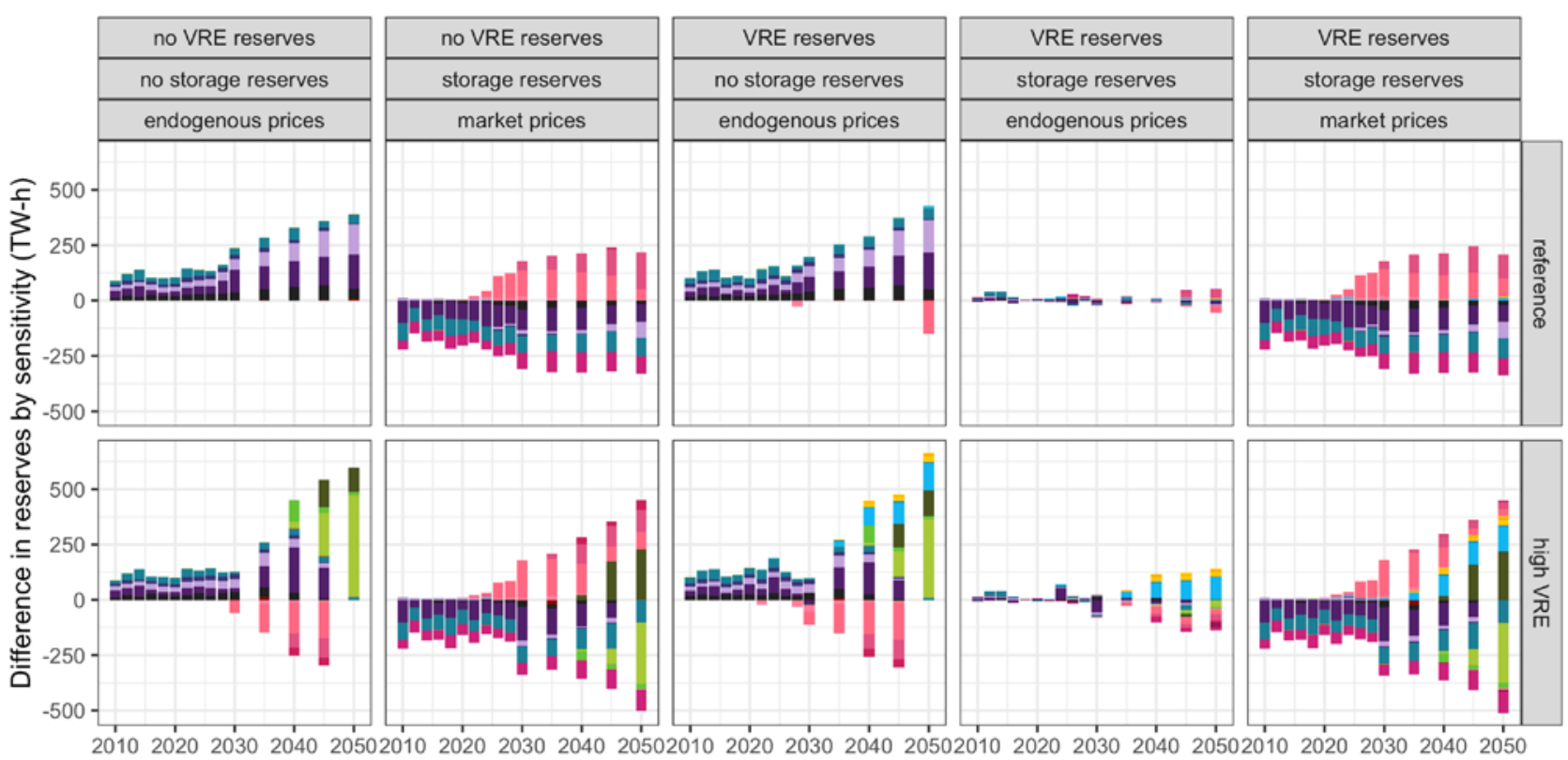




\section{ReEDS sensitivity testing: Reserve provision}

\section{Reference cases}

- Disallowing storage from providing operating reserves increases the amount provided from fossil and hydro.

- There is little VRE used for reserves, even in scenarios where it is allowed.

- Using historical market prices for reserves shifts reserve provision away from thermal resources and toward storage.

\section{High VRE cases}

- H2-CTs are used to provide operating reserves in all cases; reliance on these resources increases dramatically if storage cannot provide reserves.

- VRE is used to provide reserves when allowed, but provides a smaller share than storage and $\mathrm{H} 2-\mathrm{CTS}$ 


\section{ReEDS sensitivity testing: Reserve prices}

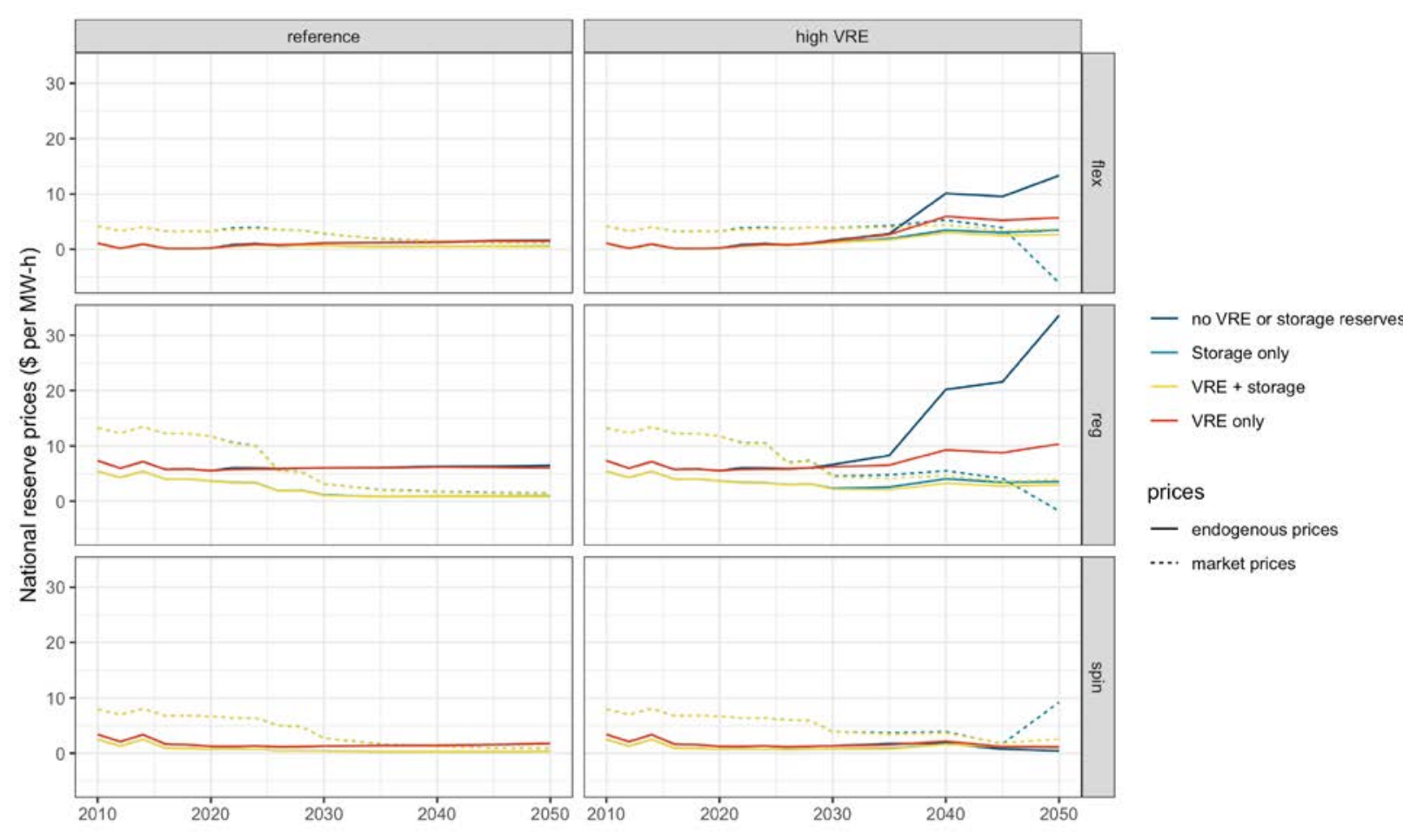

National average reserve prices computed by multiplying the price of reserves (the marginal value of the reserve constraint) with the quantity of reserves provided by BA, summing across all BAs to get total national cost of reserves, and then dividing by the total quantity of reserve procured nationally
Highest prices occur when storage is not allowed or able to provide reserves.

- Biggest impact occurs in regulation reserves.

- $\quad$ The price impacts are higher in high VRE case.

- $\quad$ Aligns with previous findings on curtailment/reserve provision (see Frew et al. "The Curtailment Paradox in the Transition to High Solar Power Systems")

Market price estimates are generally higher than the endogenous estimates in the short term but lower than them in future cases.

- ReEDS likely not capturing all of the costs for thermal resources to provide reserves.

- $\quad$ Prices for operating reserves might be expected to rise as systems move to higher shares of wind and solar. 


\section{Summary}

This project enhanced ReEDS' formulation for operating reserves:

- Improved representation of storage.

- Better constraints on generator commitment.

- $\quad$ Revised costs for generators with heat rates.

- More switches to enable users to test different aspects of reserves.

Comparison against PLEXOS runs indicates general alignment in the types of generators that provide reserves.

- There are differences between the two in which resources supply which operating reserve product, but total provision by technology is similar across the two.

- $\quad$ Some differences are expected between capacity expansion and production cost models due to differences in temporal resolution, chronological modeling, and thermal generator constraints.

Sensitivity testing suggests reserve formulations exert little influence over the solution of the model

(i.e., installed capacity, total system cost)

- However, the operating reserve formulation does impact what technologies are used to provide reserves, and thus may be important for certain analyses.

- $\quad$ Future work might further investigate the conditions in which operating reserves exert more influence over the model solution (e.g., does a capacity expansion model with higher temporal resolution better capture some of the challenges involved in procuring operating reserves?). 


\section{References}

Bloom, Aaron, et al. Eastern Renewable Generation Integration Study. 2016, https://www.osti.gov/biblio/1318192.

Denholm, Paul L., et al. An Introduction to Grid Services: Concepts, Technical Requirements, and Provision from Wind. National Renewable Energy Laboratory, Golden, CO, 2019, https://www.osti.gov/biblio/1493402.

Ela, Erik, et al. Operating Reserves and Variable Generation. National Renewable Energy Lab.(NREL), Golden, CO (United States), 2011, https://www.osti.gov/biblio/1023095.

Ferreira, S.R.; Rose, D. M.; Schoenwald, D.A.; Bray, K.; Conover, D.; Kintner-Meyer, M.; Viswanathan, V. (2013), Protocol for Uniformly Measuring and Expressing the Performance of Energy Storage Systems. SAND2013-7084. Albuquerque, NM: Sandia National Laboratories.

Frew, Bethany, et al. "The Curtailment Paradox in the Transition to High Solar Power Systems." Joule, vol. 5, no. 5, 2021, pp. 1143-67, doi:10.1016/j.joule.2021.03.021. Available at https://www.sciencedirect.com/science/article/pii/S2542435121001446.

Ho, Jonathan, et al. Regional Energy Deployment System (ReEDS) Model Documentation: Version 2020. National Renewable Energy Laboratory, Golden, CO, 2021, https://www.osti.gov/biblio/1788425.

Hummon, Marissa, et al. Fundamental Drivers of the Cost and Price of Operating Reserves. National Renewable Energy Laboratory, Golden, CO, 2013, https://www.osti.gov/biblio/1220216.

Jorgenson, Jennie, et al. Estimating the Performance and Economic Value of Multiple Concentrating Solar Power Technologies in a Production Cost Model. National Renewable Energy Laboratory, Golden, CO, 2013, https://www.osti.gov/biblio/1260920.

Lew, Debra, et al. Western Wind and Solar Integration Study Phase 2. National Renewable Energy Laboratory, Golden, CO, 2013, https://www.osti.gov/biblio/1095399. 


\section{Feel Free to Follow-up!}

\section{brian.sergi@nrel.gov \\ wesley.cole@nrel.gov}

\section{www.nrel.gov}

NREL/PR-6A40-81706

This work was authored by the National Renewable Energy Laboratory, operated by Alliance for Sustainable Energy, LLC, for the U.S. Department of Energy (DOE) under Contract No. DE-AC36-08GO28308. Funding provided by U.S. Department of Energy Office of Energy Efficiency and Renewable Energy Strategic Analysis Team, Solar Energy Technologies Office, Wind Energy Technology Office, and Water Power Technology Office. The views expressed in the article do not necessarily represent the views of the DOE or the U.S. Government. The U.S. Government retains and the publisher, by accepting the article for publication, acknowledges that the U.S. Government retains a nonexclusive, paid-up, irrevocable, worldwide license to publish or reproduce the published form of this work, or allow others to do so, for U.S. Government purposes. 


\section{eq_storage_opres formulation}

*there must be sufficient energy in storage to provide operating reserves

eq_storage_opres $(i, v, r, h, t) \$\left[\right.$ valgen $(i, v, r, t) \$ \operatorname{tmodel}(t) \$ S w \_0 p R e s$

\$(storage_standalone(i) or pvb(i) or hyd_add_pump(i))]..

*[plus] initial storage level

STORAGE_LEVEL $(i, v, r, h, t)$

*[minus] generation that occurs during this timeslice

- hours_daily $(h) * G E N(i, v, r, h, t) \$[n o t p v b(i)]$

*[minus] generation that occurs during this timeslice

- hours_daily(h) * GEN_PVB_B(i,v,r,h,t) \$[pvb(i)\$Sw_PVB]

*[minus] losses from reg reserves (only half because only charging half

*the time while providing reg reserves)

- hours_daily $(h) *$ OPRES("reg", $i, v, r, h, t) *(1-$ storage_eff $(i, t)) / 2 *$ reg_energy_frac

$=g=$

*[plus] energy reserved for operating reserves

+ hours_daily $(h) * \operatorname{sum}\{$ ortype, OPRES(ortype, $i, v, r, h, t)\}$

; 